\title{
Journal of Pre-College Engineering Education Research (J-PEER)
}

\section{Observing Empathy in Informal Engineering Activities with Girls Ages 7-14}

\author{
Susan M. Letourneau \\ New York Hall of Science, sletourneau@nysci.org \\ Dorothy T. Bennett \\ New York Hall of Science, dbennett@nysci.org \\ ChangChia Liu \\ New York Hall of Science
}

See next page for additional authors

Follow this and additional works at: https://docs.lib.purdue.edu/jpeer

Part of the Engineering Education Commons

\section{Recommended Citation}

Letourneau, S. M., Bennett, D. T., Liu, C., Argudo, Y., Peppler, K., Keune, A., Dahn, M., \& McMillan Culp, K. (2022). Observing Empathy in Informal Engineering Activities with Girls Ages 7-14. Journal of Pre-College Engineering Education Research (J-PEER), 11(2), Article 8.

https://doi.org/10.7771/2157-9288.1354

This document has been made available through Purdue e-Pubs, a service of the Purdue University Libraries. Please contact epubs@purdue.edu for additional information.

This is an Open Access journal. This means that it uses a funding model that does not charge readers or their institutions for access. Readers may freely read, download, copy, distribute, print, search, or link to the full texts of articles. This journal is covered under the CC BY-NC-ND license. 


\title{
Observing Empathy in Informal Engineering Activities with Girls Ages 7-14
}

\begin{abstract}
Empathy is a critical part of the engineering design process. It allows engineers to more deeply understand their clients' perspectives and design solutions that meet the needs of diverse stakeholders. Studies also show that reframing engineering education to prioritize empathy for others can counteract stereotypes of engineering as impersonal and invite a wider range of identities into the field. This approach can help to address persistent gender disparities in engineering, which reflect a need for engineering education to increase its efforts to include girls' perspectives. Informal learning environments have developed strategies for framing engineering problems in human-centered ways, but more evidence is needed about how children express empathy during engineering design tasks and how expressions of empathy intersect with and support specific engineering design practices in these settings. The present study involved the development of observational methods for documenting empathy within museumbased engineering activities among girls ages 7-14. Engineering activities used elements of narratives (characters, settings, and problem frames) to prompt learners to think about who they were designing for and why. Data included observations and interviews with 245 girls, and iterative cycles of coding and qualitative analyses to develop a set of observable indicators of empathy and engineering design practices. Indicators defined how multiple facets of empathy were expressed (affective, cognitive, and prosocial, as well as connections to familiar personal experiences) based on theoretical understandings of empathy and its development. Final coding of the dataset with these indicators showed that girls' expressions of empathy supported multiple engineering design practices as learners defined problems to solve, and as they generated and iterated solutions with the needs of others in mind. We describe connections between individual facets of empathy and specific engineering practices and discuss implications for practice within formal and informal settings.
\end{abstract}

\section{Keywords}

engineering design, informal learning environments, humanistic engineering education, empathy, narratives

\section{Document Type}

Invited Contributions: Best Papers from ASEE Pre-College Engineering Education

\section{Authors}

Susan M. Letourneau, Dorothy T. Bennett, ChangChia Liu, Yessenia Argudo, Kylie Peppler, Anna Keune, Maggie Dahn, and Katherine McMillan Culp 


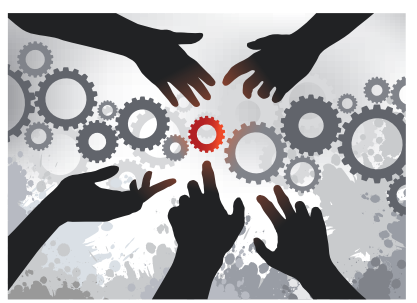

Journal of Pre-College Engineering Education Research 11:2 (2021) 120-128

\title{
Observing Empathy in Informal Engineering Activities with Girls Ages 7-14
}

\author{
Susan M. Letourneau ${ }^{1}$, Dorothy T. Bennett ${ }^{1}$, ChangChia Liu ${ }^{1}$, Yessenia Argudo ${ }^{1}$, \\ Kylie Peppler ${ }^{2}$, Anna Keune ${ }^{3}$, Maggie Dahn ${ }^{2}$, and Katherine McMillan Culp ${ }^{1}$ \\ ${ }^{1}$ New York Hall of Science \\ ${ }^{2}$ University of California, Irvine \\ ${ }^{3}$ Technical University of Munich
}

\begin{abstract}
Empathy is a critical part of the engineering design process. It allows engineers to more deeply understand their clients' perspectives and design solutions that meet the needs of diverse stakeholders. Studies also show that reframing engineering education to prioritize empathy for others can counteract stereotypes of engineering as impersonal and invite a wider range of identities into the field. This approach can help to address persistent gender disparities in engineering, which reflect a need for engineering education to increase its efforts to include girls' perspectives. Informal learning environments have developed strategies for framing engineering problems in human-centered ways, but more evidence is needed about how children express empathy during engineering design tasks and how expressions of empathy intersect with and support specific engineering design practices in these settings. The present study involved the development of observational methods for documenting empathy within museum-based engineering activities among girls ages 7-14. Engineering activities used elements of narratives (characters, settings, and problem frames) to prompt learners to think about who they were designing for and why. Data included observations and interviews with 245 girls, and iterative cycles of coding and qualitative analyses to develop a set of observable indicators of empathy and engineering design practices. Indicators defined how multiple facets of empathy were expressed (affective, cognitive, and prosocial, as well as connections to familiar personal experiences) based on theoretical understandings of empathy and its development. Final coding of the dataset with these indicators showed that girls' expressions of empathy supported multiple engineering design practices as learners defined problems to solve, and as they generated and iterated solutions with the needs of others in mind. We describe connections between individual facets of empathy and specific engineering practices and discuss implications for practice within formal and informal settings.
\end{abstract}

Keywords: engineering design, informal learning environments, humanistic engineering education, empathy, narratives

\section{Introduction}

Research and policy shifts in engineering education have identified socioemotional skills like empathy as a fundamental and often neglected part of engineering practice (Engineering Accreditation Commission, 2017; Walther et al., 2017). This work argues that solving complex engineering challenges with societal and ethical implications requires engineers to empathize with clients and colleagues whose perspectives and needs might differ from their own (Capobianco \& Yu, 2014; Hess \& Fila, 2016; Walther et al., 2017). Humanistic approaches to engineering education integrate empathy as a core skill and orientation to engineering practice, placing the other people involved in the engineering design process at the center (Hynes \& Swenson, 2013; Walther et al., 2020). This human-centered approach has the potential to strengthen engineering 
practices while also offering more welcoming invitations into the field for groups of learners, particularly women, who have historically been marginalized in engineering courses and careers. Research has found that the dominant view of engineering as primarily about "working with things" rather than "working with people" is one factor that leads young women to the conclusion that engineering is not for them (Balsamo, 2011; Diekman et al., 2010; Su \& Rounds, 2015). These conceptions of engineering begin to form in elementary and middle school, leading many girls to pursue other, more human-centered fields (Brickhouse et al., 2000; Ceci \& Williams, 2011; Eccles \& Wang, 2016). Introducing children to engineering as a profession that involves empathy and care for others can counteract perceptions that engineering is impersonal and technocentric (Brickhouse et al., 2000; Capobianco \& Yu, 2014), and informal science, technology, engineering, and mathematics (STEM) environments in particular can play a role in offering engaging introductions to engineering for girls and young women. Developing engineering experiences specifically with girls' interests and needs in mind can allow informal institutions to create innovative learning experiences that shift whose perspectives are valued, inviting a wider range of identities into the field.

Development efforts in museum settings have explored strategies for providing personal and social contexts for engineering tasks that encourage learners to empathize with others as part of the design process-for example by using narratives (e.g., characters or settings that depict clients and their problems) to invite learners to consider how to help others with their designs (Bennett, 2000; Bennett \& Monahan, 2013). Professional engineers frequently utilize narratives to help them empathize with clients and other stakeholders, understand the problems they face, and envision how they might use designed solutions (Grimaldi et al., 2013; Hunsucker \& Siegel, 2015). With the increasing recognition that empathy is critical for human-centered engineering practices, and, in turn, to ongoing efforts to broaden participation in the field, there is a need for additional research on the impact of these types of interventions on children and youth. However, a first step in this effort is developing evidence-based tools and methods for analyzing how children express empathy during engineering design tasks, and how expressions of empathy intersect with and support specific engineering design practices. In this study, we aimed to map this terrain by conducting rich qualitative observations of what empathy looked and sounded like among girls ages 7-14 as they engaged in human-centered engineering design tasks. We used iterative data-driven analyses to develop and refine a set of behavioral indicators for capturing empathy within the engineering design process in this age group (Miles et al., 2018).

\section{Theoretical Framework}

This project drew on three major bodies of research:

(1) Prior research in psychology and neuroscience defines empathy as a multifaceted process that includes three related processes: affective or emotional responses, such as emotional contagion (e.g., contagious laughter or sadness) as well as feelings of compassion or sympathy for others; cognitive perspective-taking, which involves imagining another's thoughts, feelings, or point of view; and prosocial behaviors such as altruism and other actions taken to help others (Batson, 2009; Decety \& Jackson, 2004). Although these facets of empathy begin emerging in infancy and early childhood, they continue to develop and become more sophisticated over time, supporting positive social interactions and helping behavior into adulthood (McDonald \& Messinger, 2011).

(2) Humanistic approaches to engineering build on the definitions of empathy described above by framing empathy as a malleable skill that engineers can cultivate in order to develop more ethical and human-centered approaches to their professional practice (Walther et al., 2017; 2020). This work argues that engineers must understand and empathize with their clients' problems and points of view in order to design solutions that meet their needs (Hess \& Fila, 2016). On a deeper level, empathy is not merely a means to an end, but a core orientation and way of being that supports engineers in working to improve society and collaborate with diverse stakeholders (Hynes \& Swenson, 2013; Walther et al., 2017).

(3) Finally, we drew on frameworks for K-12 engineering education, which describe engineering design practices as a central component of engineering learning at elementary and middle school levels (American Society for Engineering Education, 2020; Moore et al., 2014; National Academy of Engineering, 2019). Although there are numerous descriptions of the engineering design process, it is generally described as a cyclical and iterative process of defining a problem and planning, creating, and improving solutions (National Academy of Engineering, 2019). In this study, we aimed to understand how various facets of empathy might be expressed in the context of the engineering design process, as participants developed and improved a design with others' needs in mind. Prior research has examined empathy within the design process among engineering undergraduates, faculty, and professionals (Hess \& Fila, 2016; Rasoal et al., 2012; Strobel et al., 2013; Walther et al., 2020), but the expressions of empathy among younger children during engineering design activities remain relatively unknown. 


\section{Research Approach}

This work was conducted as part of a three-year design-based research project at a science center in the United States, which involved developing and testing six engineering activities that used elements of narratives (such as characters or settings) to evoke learners' empathy for the users of their designs. We used a design-based research approach, in which researchers and activity developers collaborate closely to develop and test new educational approaches. In design-based research, initial designs embody theoretical conjectures about how learning takes place in a given context, which are then updated based on ongoing observations as evidence is gathered (Bakker, 2018; Cobb et al., 2003). In this project, museum educators and researchers iteratively developed, tested, and refined engineering activities and research instruments to address the following research questions: (1) How do girls (ages 7-14) express empathy in the context of narrative-based engineering activities? (2) What impact do expressions of empathy have on girls' use of engineering design practices?

In this paper, we will focus on the iterative development of a framework for documenting aspects of empathy that are related to engineering design practices. Other aspects of the study (including the development of activities and design principles, comparisons of narrative and non-narrative activities on a range of engineering outcomes, and quantitative analyses of the intersections of engineering and narrative practices with empathy) are reported elsewhere (Letourneau \& Bennett, 2020; Peppler et al., 2020). We focused on gathering data about girls' experiences because our primary goal was to develop activities that would appeal to this demographic and center their needs and points of view. Our assumption throughout was that approaches that would be more inclusive for girls might also support other groups of learners who tend not to engage with traditional engineering challenges, although this is an empirical question for future studies.

\section{Methods}

\section{Procedure}

Participants included 245 girls (ages 7-14) who participated in engineering activities at an urban science center in the northeast of the United States during regular museum visits. We focused our observations on girls in order to center girls' experiences throughout the activity development process. Each girl participated in either a narrative or a non-narrative version of one of six engineering activities. Narrative versions of the activities contained characters, settings, or problem frames that were designed to evoke empathy. For example, some activities involved sympathetic characters with problems that needed to be solved (e.g., in "Help the Pets," children used simple machines to create a chain reaction contraption that could help take care of a pet; in "Help Grandma," they used repurposed materials to design and build models of inventions to help a grandparent with everyday tasks like carrying groceries). Some activities combined characters and settings, as in an activity called "Safe Landing," which invited children to design something to protect an alien or astronaut landing on the surface of a planet. In this activity, the testing station was a 20-foot drop with a space-themed background and landing pad. Other activities involved only a narrative problem frame (e.g., in "Emergency Structures," children used dowels and rubber bands to build a structure that could fit everyone in their group and withstand an earthquake). Non-narrative versions with similar engineering challenges but without the narrative framing were used for comparison (e.g., prompting children to use dowels to build a stable structure, without the earthquake narrative). See Letourneau \& Bennett (2020) for a complete list of the activities tested.

\section{Data Sources}

Data included: field notes documenting how activities were implemented (including detailed descriptions of the materials used and facilitation strategies); observations of participating girls as they completed the activity (noting the problems they decided to solve, the constraints or criteria they considered, the design ideas they generated, and how they built and iterated their designs, based on both nonverbal behaviors as well as any conversations that were overheard as girls engaged in the activities); and semi-structured interviews with each participant (in which researchers prompted participants to describe their design ideas, the problems they were trying to solve, and whether and how they considered the users of their designs).

\section{Coding and Analysis}

To develop methods for documenting empathy within these engineering activities, our data collection and analyses were conducted in three iterative phases.

First, we used open-coding of field notes, observations, and interviews from the first three activities to descriptively document how facets of empathy identified in the literature were expressed in girls' verbal and nonverbal behaviors, and 
how they intersected with engineering design practices. We began by using definitions of these categories from existing research that describes multiple facets of empathy (Batson, 2009; Decety \& Jackson, 2004; McDonald \& Messinger, 2011). This work describes affective or emotional components of empathy as involving emotional contagion, compassion, or concern for another person (e.g., feeling what someone else feels, or feeling sympathetic toward them). Cognitive facets of empathy involve understanding and/or imagining another's perspective or point of view. This is an analytical process that can take place with or without emotional engagement. Finally, some models of empathy include prosocial behaviors, which involve taking action to help others (e.g., altruism). Engineering design practices were drawn from engineering design frameworks for K-12 education (American Society for Engineering Education, 2020; Moore et al., 2014; National Academy of Engineering, 2019), which describe the design process as an iterative or cyclical process of identifying a problem and building and improving a designed solution. Based on prior studies in informal settings (Dorie et al., 2014), and our own pilot observations in our museum, we focused on the practices of problem scoping, ideation, testing, and iteration. We highlighted any instances of behaviors or responses in our observations that aligned with these aspects of empathy and engineering design practices along with when and how they were expressed. Three researchers open-coded a subset of the data in this way and discussed examples of each category, iteratively refining the categories and indicators through multiple rounds of analysis and discussion.

Next, we tested and revised this initial set of indicators by using them to guide observations and interviews in subsequent activities. Researchers gathered field notes, observations, and interviews, and after completing each observation, immediately noted any evidence of the indicators identified in the first round of data analysis. This allowed for more detailed observations of conditions surrounding these indicators, which in turn allowed the categories themselves to be iterated further. Three researchers conducted observations, and discussed the evidence gathered for each category after each testing day, revising the definitions and criteria for each indicator as needed to reach a consensus on how each indicator might be expressed.

The final set of indicators was then used to recode the entire dataset. Three researchers coded a subset of the observation and interview data (20\%), noting whether girls expressed each empathy indicator and engineering practice, and obtained interrater reliability of over $85 \%$ across coding categories. Disagreements were resolved through discussion. These categories also guided a quantitative summative evaluation across three museum sites in different regions of the United States (Peppler et al., 2020).

Throughout this process, disagreements between coders helped clarify the definitions of each behavior, as well as the ways they might be expressed in informal settings. For example, when defining iteration in our activities, we realized that we needed to consider both large-scale changes to the design made after a formal test, and smaller-scale changes made after children tested part of the design or talked with others about how the design should function, as these types of interactions were quite common in our activities and led children to adjust and improve their designs prior to larger-scale tests. In addition, when considering empathic responses such as perspective-taking, we discussed whether these behaviors could involve children referring to themselves, since children were designing for themselves and/or their families in some activities. Although empathy often implies thinking of other people's needs, we ultimately decided that considering one's own needs in an imagined scenario involves the same kinds of perspective-taking that engineers engage in through their work. For example, engineers might imagine themselves in the situation under consideration in order to understand the problems that one might encounter and the solutions that might be helpful. Therefore, we considered imagining oneself in an imagined scenario to be an indicator of perspective-taking when it was observed. This allowed us to recognize expressions of perspective-taking in younger children in our sample, who are still developing the ability to consider multiple points of view outside of their own (McDonald \& Messinger, 2011).

\section{Results}

\section{Engineering Design Practices}

Based on our iterative rounds of observation and analysis, we used the following criteria to identify engineering design practices in girls' behavior:

- Problem scoping: Identifying multiple aspects of the overall design problem, considering criteria or constraints that a design should meet.

- Ideation: Generating and planning possible solutions to the design problem, including divergent thinking, brainstorming, and considering different forms a design might take.

- Testing: This included both large-scale tests of a design's function and small-scale tests of parts of the design. In activities without formal testing stations, this could take the form of critiquing one's design on one's own or through conversation with others. 
- Iteration: Revising a design based on evidence generated through a test. We differentiated between low levels of iteration (changing a design once or twice) and high levels of iteration (persistence in making repeated changes to optimize a design).

\section{Empathy Indicators}

In defining indicators of empathy in these engineering tasks, we focused on how multiple facets of empathy were expressed, and how they intersected with the engineering practices described above. We provide definitions and examples of each category in the context of engineering design practices below, and the indicators are summarized in Table 1 .

\section{Affective responses}

Definition and examples Girls who participated in the activities expressed affective or emotional facets of empathy by considering the feelings of their clients/users, as well as how they felt in response. For example, they described how the users of their designs might feel when experiencing a problem (e.g., "It must be frustrating when you can't hear very well."; "He looks lonely!"), or when using the designed solution (e.g., "I thought she would be happy if this was easier to do"). They also sometimes described how they felt as designers-expressing concern or compassion, or describing how they might feel if faced with the same problems (e.g., "I'd be really scared if there was an earthquake!"). In our observations and interviews, researchers often observed verbal and nonverbal expressions of these emotions as children first approached the problem, as well as later in the activity when they tested out their designs, and in interviews when children described the problem they were trying to solve.

Link to engineering practices When children expressed emotional aspects of empathy, they often engaged in mode switching (Hess \& Fila, 2016; Walther et al., 2017)—switching back and forth between connecting emotionally to the design problem and engaging in analytical problem-solving to design, build, or iterate solutions. This emotional connection encouraged children to persist in solving problems with the materials or optimizing their designs. For example, in Safe Landing, when children watched their character fall down the 20-foot drop, they often expressed emotional reactions of concern and worry for their character's safety, which frequently led them to iterate and improve their designs to make them land more slowly or softly. Likewise, in Help the Pets, the desire to make the pets happy motivated children to troubleshoot problems with the individual props within their chain reaction contraptions.

\section{Cognitive perspective-taking}

Definition and examples We observed cognitive facets of empathy when girls imagined someone else's point of view (i.e., considering what someone might think about or experience when facing a problem or using a designed solution). For example, in Safe Landing, girls might talk about what their characters might see or feel while falling toward the planet. Children also sometimes put themselves in others' shoes by pretending to be the user/client, describing or acting out how designs would be used. For example, in Emergency Structures, some younger children pretended that there was an earthquake coming and rushed to finish their structures and get inside. In Help Grandma, children frequently physically demonstrated how Grandma would use the designs that they created. In observations and interviews, researchers could determine whether children were thinking this way by prompting them to describe what they were thinking about while building, or to share the reasoning behind their design decisions.

Table 1

Definitions and examples of empathy indicators in the context of engineering design tasks.

\begin{tabular}{ll}
\hline Empathy indicator & Examples \\
\hline $\begin{array}{c}\text { Affective responses: talking about the client's/user's } \\
\text { feelings; expressing concern, compassion, sympathy }\end{array}$ & "He looks lonely" while looking at one of the pets in Help the Pets \\
& "That'll make her happy" while thinking about a solution in Help Grandma \\
& "I feel bad for him! I hope he's ok!" after testing a design in Safe Landing \\
Cognitive perspective-taking: imagining what users want or & Talking about what it would be like to be in an earthquake while designing a structure \\
need, or how someone would use a designed solution & Modeling how grandma would use a device to help her open jars \\
Prosocial desire to help: expressing a desire or taking action & $\begin{array}{c}\text { Reinforcing a dowel structure to protect those inside } \\
\text { to help the potential user of a design }\end{array}$ \\
$\begin{array}{c}\text { Familiarity: connecting to one's own personal experiences. } \\
\text { Supports other expressions of empathy above }\end{array}$ & $\begin{array}{c}\text { Thinking about one's own grandparents and the problems they faced or the things they } \\
\text { found helpful; remembering one's own pets and their preferences or needs }\end{array}$ \\
\hline
\end{tabular}


Link to engineering practices This type of perspective-taking arose most commonly during problem scoping and iteration, when girls defined the problem they were trying to solve and when they were trying to improve on their designs. This resulted in more human-centered design decisions that considered what it would be like for someone to use a designed solution. For example, in Help Grandma, one child created an invention to help a fictional grandmother who had trouble opening jars. In iterating her design for a jar-opener, she added an adjustable opening for different sized jars, and padded handles to make it more comfortable to use. In Safe Landing, another child added a porthole in her design so that her character could see outside during the journey. Our early analyses defined "user-centered design" as a separate indicator, but in later phases of work, we realized that these decisions actually reflected an intersection of empathy and engineering design practices (i.e., this was how engineering design practices were expressed when approached from an empathetic perspective).

\section{Prosocial responses}

Definition and examples Girls expressed prosocial aspects of empathy by expressing and/or acting on a desire to help or protect someone with their designs. Sometimes children would express this desire spontaneously before identifying solutions to the problem (e.g., in Help the Pets, saying "oh no, how can we feed him?"), or when making iterations to their designs, particularly changes that were meant to make designs safer or more comfortable for someone else (e.g., in Emergency Structures, reinforcing a dowel structure "to make sure that we survive"). In interviews, questions asking children to describe their designs and their reasoning behind their design decisions were effective at revealing this facet of empathy as well.

Link to engineering practices A prosocial desire to help supported initial phases of problem scoping and ideation. In interviews, when describing the problem they were trying to solve, girls often described being motivated by wanting to help someone. In addition, this facet of empathy also appeared while children made additional iterations to their designs that focused on ensuring the safety and well-being of clients/users. In a later evaluation, some children extended this to include prosocial consideration of larger societal or environmental issues (e.g., sustainability, protecting ecosystems/habitats).

\section{Familiarity}

Both the design-based research as well as the summative evaluation found that girls often identified with the users of their designs by making a connection to their own prior experiences. This was different from simply using prior content knowledge; instead, this indicator was evidenced by children referencing personal experiences, memories, or relating some aspect of the problem either to their own lives or to those of their friends or family members. For example, in the activity focused on helping grandmothers, children often mentioned their own grandparents and the kinds of things that they needed help doing, or the kinds of solutions that had helped their grandparents in the past. In prior research on empathy, familiarity is considered a mediating factor that supports one's ability to empathize with others (Hunsucker \& Siegel, 2015). Thus, although it is not an aspect of empathy per se, we included it as a relevant indicator of empathic engineering experiences.

Refining these behavioral indicators allowed us to iteratively develop activities that evoked empathy in ways that bolstered engineering learning for girls in our target age group. Our design-based research showed that the narrative versions of the activities were effective in evoking multiple facets of empathy (Letourneau \& Bennett, 2020), and when girls expressed at least one indicator of empathy, they stayed longer and demonstrated more engineering practices (Peppler et al., 2020). Although our focus here is on describing our observational methods, these findings highlight the value of rigorously documenting empathy alongside engineering practices in order to develop more inclusive and human-centered approaches to engineering education.

\section{Discussion}

This research study investigated how 7- to 14-year-old girls express empathy within the engineering design process. We brought together prior research on empathy, engineering education, and museum practice to document multiple facets of empathy and their role in supporting specific engineering design practices, such as problem scoping, ideation, testing, and iteration. Using a qualitative and data-driven analytical process, we focused on understanding empathy as an integral part of the engineering design process for children in elementary and middle school, a critical period when children begin to form conceptions of engineering as a field. Our ultimate goal was to generate evidence to inform the development of inclusive activities that presented engineering as an empathic and human-centered endeavor.

By providing tools for capturing both empathic thinking and engineering design practices in this age group, this study could allow educators and researchers to design and study interventions that are targeted toward the intersections between these two processes. For example, educators may use these indicators to develop engineering activities that evoke one or 
more facets of empathy, to notice expressions of empathy in their students, and to scaffold empathic approaches to solving engineering problems. Likewise, researchers may use these indicators to explore what qualities of engineering activities can support specific empathic responses, how expressions of empathy might vary across age groups, cultures, or settings, and the impact on other aspects of engineering learning (such as engineering knowledge, materials fluency, habits of mind, engineering identity, etc.).

Although we focused our efforts on understanding and supporting girls' experiences with these activities, given their persistent underrepresentation in the field, our assumption throughout was that narrative-based educational approaches that supported girls' learning might also support other groups of learners who also tend to be less engaged by traditional engineering challenges, although this is an empirical question for future studies. Further research could explore whether and how narratives can be broadly appealing to a wide range of audiences across genders and backgrounds, and whether the impacts of narratives on empathy and engineering learning vary for different audiences.

\section{Implications for Teaching and Learning}

These results have implications for the design and facilitation of more gender-inclusive engineering activities that center the personal and social dimensions of engineering. In our work, we found that layering elements of narrative onto engineering activities (in the form of characters, settings, and/or narrative problem frames) was effective in evoking multiple aspects of empathy. These strategies were most effective when they provided an evocative context for engineering problems, while leaving room for learners to decide who they wanted to help and what problems to solve within the situations we presented (Letourneau \& Bennett, 2020). This suggests opportunities to redesign a wide range of traditional, decontextualized engineering challenges in more open-ended and human-centered ways and highlights the importance of welcoming learners' own experiences and imaginations into engineering activities to deepen empathy and engagement in engineering practices.

In addition, we found that educators and facilitators played an important role in using empathy and human-centered language to prompt learners to think about who they were designing for while learners planned, built, and improved their designs. Activities and lessons might be structured to reference and reinforce the human context of engineering problems at multiple points throughout the engineering design process - presenting empathy for others as an integral skill and a valid and valuable way of understanding and solving engineering problems, in line with the framework proposed by Walther et al. $(2017,2020)$. Our work suggests that expressions of empathy within engineering can be noticed and fostered in children as young as 7 , potentially shifting their conceptions of engineering as a field and their interest in pursuing engineering courses and careers (Capobianco \& Yu, 2014).

\section{Conclusion}

This study adds to the growing body of research suggesting that reframing engineering tasks to prioritize empathy can create more inclusive entry points into engineering for many learners, and particularly girls, by inviting learners to solve design problems in order to help others (Capobianco \& Yu, 2014; Diekman et al., 2010). Such humanistic approaches can make engineering more accessible and appealing by positioning socioemotional skills like empathy as a relevant and valued part of the engineering design process. Critically, our research suggests that fostering empathy can more deeply engage girls in engineering tasks, while also supporting critical engineering practices (such as problem scoping) that can be difficult to support in more constrained educational settings that underemphasize the personal or social contexts surrounding engineering problems. In these ways, our work supports the conclusion that empathic approaches to engineering education can welcome girls' perspectives and encourage all learners to cultivate the skills and habits of mind that are necessary for solving complex real-world problems.

\section{Acknowledgments}

This material is based upon work supported by the National Science Foundation under Grant No. 1712803. Any opinions, findings, conclusions, or recommendations expressed in this material are those of the authors and do not necessarily reflect the views of the National Science Foundation. This paper is part of a set of papers recognized by the American Society for Engineering Education (ASEE)'s Pre-College Engineering Education Division as one of the division's best papers from the 2021 conference. J-PEER republishes the ASEE Pre-College Engineering Education Division's best papers with permission from ASEE and under the "Invited Contributions: Best Papers from ASEE PreCollege Engineering Education" section of the journal. J-PEER acknowledges that ASEE holds the copyright for this paper, the original version of which can be accessed at: Letourneau, S. M., Bennett, D., Liu, C. J., Argudo, Y., Peppler, K., Keune, 
A., Dahn, M., \& Culp, K. M. (2021, July). Observing empathy in informal engineering activities with girls ages 7-14 (RTP, Diversity). Proceedings of the 2021 ASEE Virtual Annual Conference \& Exposition, Virtual Online. https://peer.asee.org/ 37531. The authors would like to thank the following individuals who contributed to the research and development efforts throughout this project: Ashlee Bailey, Jelena Begonja, Lauren Cage, Sam Dean, Joel Gordon, Drew Lauderdale, Sophia Madonia, Amelia Merker, Satbir Multani, Leah Persram, Mindy Porter, Katherine Ozawa, Amanda Reed, Kristian Roopnarine, Dana Schloss, and Prinda Wanakule. We also thank project advisors Sue Allen, Keith Braafladt, Emily Reardon, Paula Hooper, Peggy Monahan, and Joachim Walther.

\section{Author Bios}

Susan Letourneau is a senior research associate at the New York Hall of Science. She collaborates with educators and designers to develop and study practices for creating inclusive museum experiences that emphasize play, exploration, and creative expression as avenues for STEM learning. Email: sletourneau@nysci.org

Dorothy Bennett is Director of Creative Pedagogy at the New York Hall of Science. She has over 25 years of experience researching gender equity and design-based STEM education, and leads the development of digital tools, educator professional development programs, and exhibit experiences that foster curiosity and creative problem-solving. Email: dbennett@nysci.org

ChangChia James Liu is a senior research associate at the New York Hall of Science. His work focuses on motivation in informal learning environments. His recent projects include developing and evaluating STEM-related programs, curriculums, and activities for children and families, and conducting research on museum educators' professional development. Email: jliu@nysci.org

Yessenia Argudo is a research and development assistant at the New York Hall of Science. She holds a Master of Public Health in community health education from CUNY School of Public Health and Public Policy. Email: yargudo@nysci.org

Kylie Peppler is an associate professor of Informatics \& Education at University of California, Irvine. She engages in research that focuses on the intersection of arts, computational technologies, and interest-driven learning. Email: kpeppler@uci.edu

Anna Keune is an assistant professor at the Technical University of Munich, School of Social Sciences and Technology, Department of Educational Sciences. With a background in new media art and design, Anna's research lies at the intersection of learning sciences and design scholarship with an aim toward equitable STEM education. Email: anna.keune@tum.de

Maggie Dahn is an associate project scientist at University of California, Irvine in the Connected Learning Lab and Creativity Labs. She received her PhD from UCLA's Graduate School of Education \& Information Studies in 2019 with support from an NAEd/Spencer Foundation Dissertation Fellowship. Email: dahnm@uci.edu

Katherine McMillan Culp is Chief Learning Officer at the New York Hall of Science. She leads collaborative, multidisciplinary teams to design, develop, implement, and study experiences, tools, and media that help highly diverse groups of young people discover their own identities as scientists and engineers. Email: kculp@nysci.org

\section{References}

American Society for Engineering Education. (2020). Framework for P-12 Engineering Learning. American Society for Engineering Education. https:// p12framework.asee.org/

Bakker, A. (2018). Design research in education: A practical guide for early career researchers. Routledge.

Balsamo, A. (2011). Designing culture: The technological imagination at work. Duke University Press.

Batson, C. D. (2009). These things called empathy: Eight related but distinct phenomena. In J. Decety \& W. Ickes (Eds.), The social neuroscience of empathy (pp. 16-28). MIT Press.

Bennett, D. (2000). Inviting girls into technology: developing good educational practices. Tech-savvy: Educating girls in the new computer age. American Association of University Women Educational Foundation, Commission on Technology, Gender, \& Teacher Education. http://stelar.edc.org/sites/stelar. edc.org/files/TechSavvy.pdf

Bennett, D., \& Monahan, P. (2013). NYSCI Design Lab: No bored kids! In M. Honey \& D. Kanter (Eds.), Design, make, play: Growing the next generation of STEM innovators (pp. 52-67). Routledge.

Brickhouse, N. W., Lowery, P., \& Schultz, K. (2000). What kind of a girl does science? The construction of school science identities. Journal of Research in Science Teaching, 37(5), 441-458. https://doi.org/10.1002/(SICI)1098-2736(200005)37:5<441::AID-TEA4>3.0.CO;2-3

Capobianco, B. M., \& Yu, J. H. (2014). Using the construct of care to frame engineering as a caring profession toward promoting young girls' participation. Journal of Women and Minorities in Science and Engineering, 20(1), 21-33. https://doi.org/10.1615/JWomenMinorScienEng.2014006834

Ceci, S. J., \& Williams, W. M. (2011). Understanding current causes of women's underrepresentation in science. Proceedings of the National Academy of Sciences, 108(8), 3157-3162. https://doi.org/10.1073/pnas.1014871108

Cobb, P., Confrey, J., DiSessa, A., Lehrer, R., \& Schauble, L. (2003). Design experiments in educational research. Educational Researcher, 32(1), 9-13. https://doi.org/10.3102/0013189X032001009 
Decety, J., \& Jackson, P. L. (2004). The functional architecture of human empathy. Behavioral and Cognitive Neuroscience Reviews, 3(2), 71-100. https:// doi.org/10.1177/1534582304267187

Diekman, A. B., Brown, E. R., Johnston, A. M., \& Clark, E. K. (2010). Seeking congruity between goals and roles: A new look at why women opt out of science, technology, engineering, and mathematics careers. Psychological Science, 21(8), 1051-1057. https://doi.org/10.1177/0956797610377342

Dorie, B. L., Cardella, M. E., \& Svarovsky, G. N. (2014, June). Capturing the design thinking of young children interacting with a parent. Paper presented at 2014 ASEE Annual Conference \& Exposition, Indianapolis, Indiana. https://doi.org/10.18260/1-2--20147

Eccles, J. S., \& Wang, M. T. (2016). What motivates females and males to pursue careers in mathematics and science? International Journal of Behavioral Development, 40(2), 100-106. https://doi.org/10.1177/0165025415616201

Engineering Accreditation Commission. (2017). Criteria for accrediting engineering programs. Accreditation Board for Engineering and Technology. https://www.abet.org/accreditation/accreditation-criteria/criteria-for-accrediting-engineering-programs-2018-2019/

Grimaldi, S., Fokkinga, S., \& Ocnarescu, I. (2013). Narratives in design: A study of the types, applications and functions of narratives in design practice. In M. Blythe (Ed.), Proceedings of the 6th International Conference on Designing Pleasurable Products and Interfaces (pp. 201-210). Association for Computing Machinery. https://doi.org/10.1145/2513506.2513528

Hess, J. L., \& Fila, N. D. (2016). The manifestation of empathy within design: findings from a service-learning course. Codesign, 12(1-2), 93-111. https:// doi.org/10.1080/15710882.2015.1135243

Hunsucker, A. J., \& Siegel, M. A. (2015). Once upon a time: Storytelling in the design process. Proceedings of the 3rd International Conference for Design Education Researchers (Vol. 1, pp. 443-454). http://doi.org/10.13140/RG.2.1.1200.7520

Hynes, M., \& Swenson, J. (2013). The humanistic side of engineering: Considering social science and humanities dimensions of engineering in education and research. Journal of Pre-College Engineering Education Research (J-PEER), 3(2), Article 4. https://doi.org/10.7771/2157-9288.1070

Letourneau, S. M., \& Bennett, D. (2020). Using narratives to evoke empathy and support girls' engagement in engineering. Connected Science Learning, 3(3). https://www.nsta.org/connected-science-learning-july-2020/using-narratives-evoke-empathy-and-support-girls-engagement

McDonald, N. M., \& Messinger, D. S. (2011). The development of empathy: How, when, and why. In A. Acerbi, J. A. Lombo, \& J. J. Sanguineti (Eds.), Moral behavior and free will: A neurobiological and philosophical approach (pp. 333-359). IF Press.

Miles, M. B., Huberman, A. M., \& Saldaña, J. (2018). Qualitative data analysis: A methods sourcebook (4th ed.). SAGE Publications.

Moore, T. J., Glancy, A. W., Tank, K. M., Kersten, J. A., Smith, K. A., \& Stohlmann, M. S. (2014). A framework for quality K-12 engineering education: Research and development. Journal of Pre-college Engineering Education Research (J-PEER), 4(1), Article 2. https://doi.org/10.7771/2157-9288.1069

National Academy of Engineering (2019). Link engineering educator exchange: Engineering design process models. National Academy of Engineering. https://www.linkengineering.org/Explore/EngineeringDesign/5824.aspx

Peppler, K., Keune, A., Dahn, M., Bennett, D., \& Letourneau, S. (2020). Designing for empathy in engineering exhibits. In B. Tangney, J. R. Byrne, \& C. Girvan (Eds.), Proceedings of the 2020 Constructionism Conference: Exploring, Testing and Extending our Understanding of Constructionism (pp. 80-81). http://www.constructionismconf.org/wp-content/uploads/2020/05/C2020-Proceedings.pdf

Rasoal, C., Danielsson, H., \& Jungert, T. (2012). Empathy among students in engineering programmes. European Journal of Engineering Education, 37(5), 427-435. https://doi.org/10.1080/03043797.2012.708720

Strobel, J., Hess, J., Pan, R., \& Wachter Morris, C. A. (2013). Empathy and care within engineering: Qualitative perspectives from engineering faculty and practicing engineers. Engineering Studies, 5(2), 137-159. https://doi.org/10.1080/19378629.2013.814136

Su, R., \& Rounds, J. (2015). All STEM fields are not created equal: People and things interests explain gender disparities across STEM fields. Frontiers in Psychology, 6, Article 189. https://doi.org/10.3389/fpsyg.2015.00189

Walther, J., Miller, S. E., \& Sochacka, N. W. (2017). A model of empathy in engineering as a core skill, practice orientation, and professional way of being. Journal of Engineering Education, 106(1), 123-148. https://doi.org/10.1002/jee.20159

Walther, J., Brewer, M. A., Sochacka, N. W., \& Miller, S. E. (2020). Empathy and engineering formation. Journal of Engineering Education, 109(1), 11-33. https://doi.org/10.1002/jee.20301 